\title{
Autoria e informação visual: design e artes gráficas no projeto editorial do século 20
}

\author{
Authorship and visual information: design and graphic arts in a 20th century \\ publishing project
}

\author{
Cristiane Alcântara \& Monica Tavares
}

Discursividade; Autoria; Design; Artes gráficas, Século XX

\begin{abstract}
Apoiadas no que diz Michel Foucault sobre o conceito de 'função autor', este trabalho foi desenvolvido com base na hipótese de que certos indivíduos produzam subjetividades ao determinarem regras próprias dentro de discursos coletivos. Logo, perguntamos se seria possível analisar os posicionamentos de artistas gráficos e designers por meio de seus discursos visuais. Para tanto, nossa investigação analisou certos projetos editoriais buscando examiná-los sob o viés da autoria: de 1920, destacamos J. Carlos e o capista Poty, oriundos da produção editorial voltada à cultura de massa; de 1930 e 40, o grupo de Di Cavalcanti, Tarsila do Amaral, Flávio de Carvalho e Lasar, propulsores de experimentações estéticas e de linguagem no âmbito da informação visual; e entre os anos de 1950 e 60, os construtivistas Ivan Serpa, Emilie Chamie, Moysés Baumstein e Amílcar de Castro, de discurso racionalista.
\end{abstract}

\section{Discursiveness; Authorship; Design; Graphic arts, 20th century}

Based on what Michel Foucault says on the concept of the 'author-function', this study was based on the hypothesis that certain individuals produce subjectivities by determining their own rules within collective discourses. We therefore asked whether it would be possible to analyze the positions of graphic artists and designers through their visual discourses. In order to do so, our investigation analyzed certain editorial projects from the perspective of authorship: from the 1920s, we highlight the work of J. Carlos and the cover designer Poty in from the editorial production directed to the mass culture of the 1930s and 1940s; that of Di Cavalcanti, Tarsila do Amaral, Flávio de Carvalho and the Lasar group, the forerunners of aesthetic and language experiments in the field of visual information; and in the 1950s and 1960s the rationalist discourse of the constructivists Ivan Serpa, Emilie Chamie, Moysés Baumstein and Amílcar de Castro.

\section{Introdução}

Fundamentado no que diz o filósofo Michel Foucault (2002, p. 42-46), em relação ao conceito de 'função autor'", o presente trabalho foi desenvolvido por meio da hipótese de que certos indivíduos produzam subjetividades ao determinarem regras próprias dentro de discursos coletivos, sendo estes, a partir de então, ordenados às maneiras de cada autor. Diante disso, perguntamos se seria possível analisar os posicionamentos de artistas gráficos e designers, inseridos a seus grupos e vertentes, buscando compreender tais discursos subjetivos.

A fim de encontrar respostas a este questionamento, nossa investigação objetivou analisar a informação visual vinculada ao projeto editorial, com o intuito de examiná-lo sob o viés do tema da autoria - apoiada à noção de propriedade ou à de anonimato que permita o posicionamento ou o deslocamento do autor em (ou para) novos lugares de poder.

\footnotetext{
${ }^{1}$ Foucault pontua as posições do sujeito da formação discursiva e, quando ocorre regularidade, ordem de correlações, posições e funcionamento, dá-se a posição autor ou a chamada função-autor.

Anais do 9 $\mathrm{CIDI}$ e 9 CONGIC

Luciane Maria Fadel, Carla Spinillo, Anderson Horta, Cristina Portugal (orgs.)

Sociedade Brasileira de Design da Informação - SBDI

Belo Horizonte | Brasil | 2019

ISBN 978-85-212-1728-2
} 


\section{A informação visual em altas tiragens e os discursos coletivos nos anos de $\mathbf{1 9 2 0}$}

Iniciaremos nossa abordagem investigativa partindo da década de 1920 e destacando o fato de que artistas inseridos ao universo das artes gráficas têm seus discursos construídos coletivamente em meio à urgência da produção em altas tiragens, alteram-se assim os tempos de criação e as trocas entre seus processos, que se democratizam, assim como seus repertórios são ampliados por meio de um extenso leque de influências externas. Para Agreli (2013, p. 54), é clara a relação histórica entre artes visuais e artes gráficas quando, mesmo sem a necessidade de cumprir uma função utilitária, vários grupos e movimentos, no decorrer da arte moderna, passam a discursar em uma defesa ideológica do "caráter utilitário da obra de arte, quando sentem a necessidade de uma ligação maior entre arte e vida, arte e cotidiano e arte voltada para o povo" (Agreli, 2013, p. 54).

Figura 1: Capa de 'Versos de trilussa', de Belmonte, 1928. Fonte: MELO, Chico Homem de (org), 2008, p. 113 e, na sequência, detalhe de assinatura de J. Carlos em capa da revista 'Para todos'. Fonte: Acervo pessoal da autora.

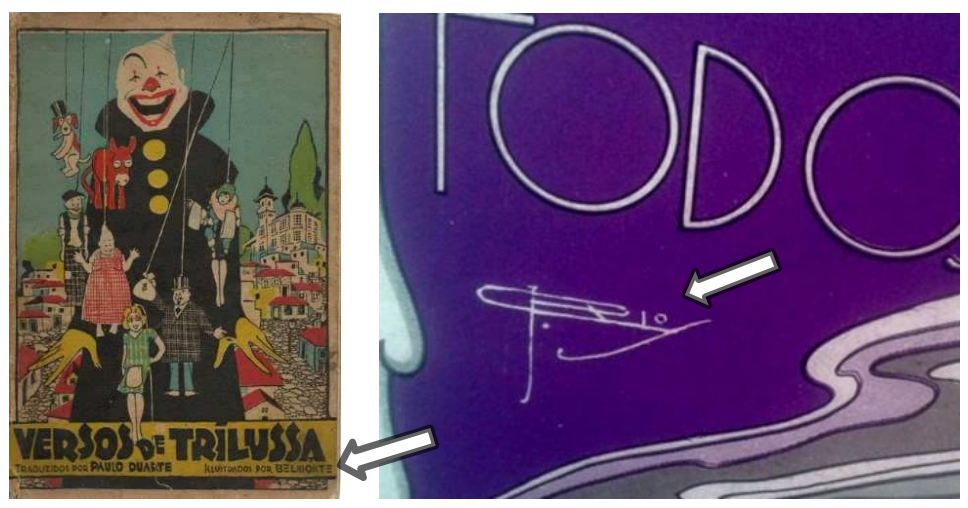

Em contraponto, este fato é menos observado no grupo definido como sendo o dos modernistas vinculados às artes plásticas, como é possível notar a ausência de assinatura nas capas produzidas por Tarsila do Amaral.

Figura 2: 'Primeiro caderno de alumno de poesia', capa de Tarsila do Amaral, 1932, Fonte: MELO, Chico Homem de (org), 2008, p. 123.



Dessa maneira, percebe-se que, naquele momento, uma importante ruptura ocorre no posicionamento daqueles autores que passam a encarar um novo modo de se colocar diante de sua obra e do protagonismo, tanto seu, quanto de sua criação. A partir da teoria de Foucault (2005, p. 37) acerca dos aspectos de poder existentes em qualquer campo do saber, é possível esclarecer uma série de jogos de poder claramente ideológicos e que nortearam os discursos 
existentes durante a transição das belas artes para as chamadas artes aplicadas, até a afirmação dos preceitos do design como campo. Neste ponto específico, a teoria foucaultiana possibilita a revisão da ideia de neutralidade discursiva própria deste período, assim como a de anonimato, na utilização de modelos durante a afirmação do design como campo e de alguns discursos artísticos, como, por exemplo, aqueles fundamentados pelo construtivismo e que defenderão a eliminação do gesto como sinal das mãos e o uso do rigor purista do esquadro e da geometria. Logo, tal prática discursiva evidencia o autor em enunciados, tanto ideológicos, quanto ordenados por conhecimento, portanto, isentos de neutralidade, uma vez que evidenciam o saber nas diferentes imposições propostas:

(...) ninguém entrará na ordem do discurso se não satisfizer a certas exigências ou se não for, de início, qualificado para fazê-lo. Mais precisamente: nem todas as regiões do discurso são igualmente abertas e penetráveis; algumas são proibidas (diferenciadas e diferenciantes), enquanto outras parecem quase abertas a todos os ventos e prosas, sem restrição prévia, à disposição de cada sujeito que fala (Foucault, 2005, p. 37)

Neste sentido, o fato de alguns daqueles autores não assinarem seus trabalhos ou de buscarem manter o anonimato devido ao fato de estarem diante de um suporte que, já naquele momento, não deveria priorizar o trabalho do artista, não os eximiria de assumir algumas posições ideológicas e de poder.

Exemplo disso é o trabalho de J. Carlos que, em uma mesma década, produziu grande quantidade de capas em que empregava claramente um discurso bastante singular, ainda que utilizasse a influência do discurso gráfico das revistas populares e um forte apelo visual. Sua narrativa era construída por meio de uma espécie de crônica visual a partir de sua observação da vida cotidiana do Rio de Janeiro de sua época e não possuía o apelo engajado em transformar o mundo, o que era próprio das vertentes eruditas da arte daquele contexto. Em contrapartida, objetivava registrar de forma lúdica, tanto os tropeços, quanto as maravilhas de tempos fortemente associados ao fugaz, em que tal fugacidade teria como base o intuito de se comunicar com o imaginário de uma série de leitores que buscavam ou em que ecoavam o discurso lúdico de apelo popular, próprio das revistas ilustradas.

Logo, a composição dos discursos de J. Carlos teria como origem, além do universo das revistas populares da época, a linguagem do Art-Déco, dado visto que, num momento em que a ideia de coletivo estava cada vez mais associada ao totalitarismo, estilo mais pragmático do que utópico, se endereçava ao desejo e à fantasia de cada um"2.

Figura 3: Melindrosa em capa da revista 'Para Todos', de J. Carlos. Fonte: J. Carlos em Revista [Catálogo]. São Paulo: Centro Cultural Correios e Instituto Memória Gráfica Brasileira, p. 63

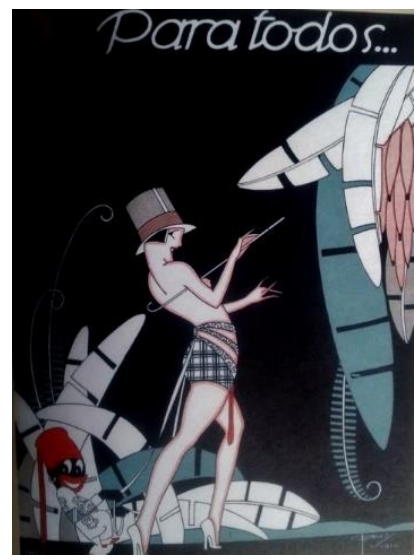

Neste cenário, ainda que reconhecidamente os discursos de J. Carlos parecessem diluídos em uma exterioridade coletiva, sua obra demonstra uma série de elementos que enfatizam a criação de modos de subjetivação. Ao mesmo tempo, o artista produziu capas como para

\footnotetext{
2 Em J. Carlos em Revista [Catálogo]. São Paulo: Centro Cultural Correios e Instituto Memória Gráfica Brasileira, p. 14.
} 
Ilustração Brasileira, em que usava códigos específicos, referentes àquela publicação, o que denota como "(...) sabia modular a voz de acordo com as características editoriais do veículo que estava projetando" (Melo, C. H. de, 2008, p. 129), o que reforça a afirmação foucaultiana de que o sujeito não se situa de maneira estática dentro dos campos discursivos. Logo, o fato de J. Carlos utilizar códigos, preceitos mais técnicos ou modelos, assim como de descartar o uso da assinatura em determinadas obras, evidencia a atuação do sujeito diluído entre seus campos de discursividade, haja vista que "no homem, o interior é também o exterior (...)" (Foucault, 2002, p. 511).

Também é importante ressaltar que, de acordo com a noção de sujeito, quando J. Carlos coloca-se claramente como autor - como nas capas da revista 'Para Todos' em que as assinava e utilizava uma linguagem caracterizada por suas melindrosas, ou quando cria um universo tipográfico "com características que nos parecem surpreendentes e inusitadas até hoje"3, ainda assim, também estaria diluído como sujeito em posições externas e coletivas do campo discursivo. O que denota o pensamento foucaultiano e das vertentes estruturalistas, de que, assim como não exista criador único e absoluto, também não haja o discurso neutro.

Michel Pêcheux (1998) recusa a neutralidade em qualquer campo em que o sujeito se encontre. Para este autor não existem discursos neutros constituídos com base na ilusão de que alguém não esteja tomando posição diante de qualquer enunciado, ainda que seja nos discursos pautados na razão, na geometria e em modelos pré-definidos. Para isto, Pêcheux centraliza esta ideia na importância da ideologia enquanto constitutiva dos discursos, ideia reforçada também por Orlandi: "não há discurso sem sujeito nem sujeito sem ideologia" (Orlandi, 1996, p. 13).

Fato é que o grupo de J. Carlos, vinculado à produção editorial de cunho mais popular ou às grandes editoras, possuía seus discursos associados fortemente à cultura de massa, o que os determinava como sujeitos diante de algumas características próprias deste meio.

Entretanto, este fato não impediu que muitos deles ordenassem seus discursos de modo singular, em posições autorais e de conduta na criação de regras e modelos. É o que demonstra, por exemplo, citação encontrada no catálogo da exposição comemorativa da obra de J. Carlos, ocorrida no ano de $2016^{4}$, em que se destaca o caráter ideológico do discurso, apontando a importância de J. Carlos para a arte nacional, assim como de seu poder em influenciar e conduzir gerações futuras:

Liberdade, precisão e elegância parecem ter sido as palavras-chave desse percurso. Ver seu legado, aos poucos, a influenciar as novas gerações faz crer que talvez tenhamos começado a romper com o mais perverso de nossos paradigmas - a crença de que o melhor vem sempre de fora; que nosso talento, para ser reconhecido por nós, precisa antes ser reconhecido além-mar 5 .

\section{Do discurso de brasilidade à criação de informação visual}

De discurso fortemente ideológico e nacionalista se formou a primeira turma de modernistas a partir de 1920, no Brasil. Com o objetivo de descobrir um Brasil verdadeiro, de conhecer e reinterpretar a partir das peculiaridades nacionais as diferentes vertentes das vanguardas europeias e da criação de um espirito novo, condizente com aqueles novos tempos, os modernistas pareciam parte de um mesmo coro, do qual, segundo Mário de Andrade, "a semana moderna ficou sendo o brado coletivo principal" (Andrade como citado em Almeida, 2014, p. 45).

Sem uma determinação única de cânones ou regras de linguagem, os discursos em torno do grupo dos primeiros modernistas parecem unânimes na ideia de que a única regra deveria ser a liberdade, no "direito permanente à pesquisa; a atualização da inteligência artística brasileira; e a estabilização de uma consciência criadora nacional" (Almeida, 2014, p. 47).

\footnotetext{
3 Ibid, p. 85.

4 Exposição apresentada pelo Centro Cultural Correios e Instituto Memória Gráfica Brasileira no ano de 2016, intitulada J. Carlos em Revista, São Paulo.

5 Em J. Carlos em Revista [Catálogo]'. São Paulo: Centro Cultural Correios e Instituto Memória Gráfica Brasileira, 2016, p. 15.
} 
Nos anos de 1930 e 40, no grupo em que se inserem Di Cavalcanti, Tarsila do Amaral, Flávio de Carvalho e Lasar Segall, ligado às artes plásticas e ao discurso de brasilidade, iremos destacar que as pesquisas e experimentações estéticas e de linguagem produzidas por aqueles artistas visuais geraram grandes inovações na produção da informação visual no país, inclusive na utilização de técnicas e de suportes. Especificamente na produção editorial do livro destacam-se Di Cavalcanti, que tem sua carreira dividida entre a produção artística e a vinculada ao design gráfico e, ainda, Tarsila do Amaral, Flávio de Carvalho e Lasar Segall.

Já nas primeiras capas de Di Cavalcanti, produzidas no final dos anos de 1910, é possível observar a distinção entre seu discurso visual e a produção de massa da época. Em 'Ballada do enforcado' o autor não assina a capa e abandona a referência figurativa, própria de seu trabalho em outros suportes.

Figura 4: Capa do livro 'Ballada do enforcado', de Di Cavalcanti, 1919 e, na sequência capa do livro 'Jardim das confidencias', de Di Cavalcanti, 1921. Fonte: MELO, Chico Homem de (org), 2008, p. 107 e p. 75
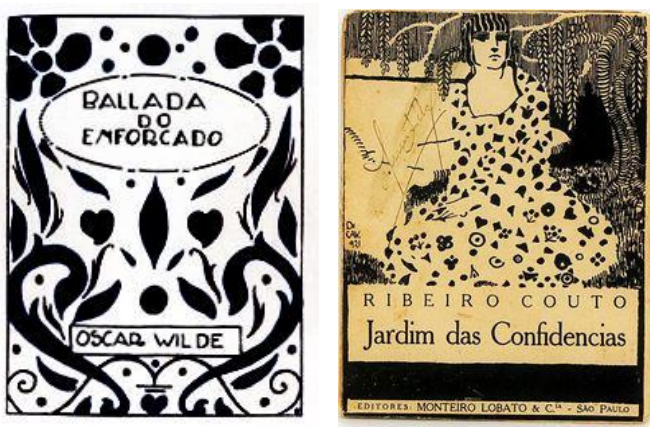

Publicados por Monteiro Lobato, 'Jardim das confidencias' (Figura 5) e 'Fantoches da meianoite' (Figura 7) são outros dois títulos produzidos por Di Cavalcanti, o segundo, por ser um álbum de folhas soltas, é considerado bastante moderno para a época, trata-se "da obra de um artista visual que se apresenta na forma de uma peça gráfica” (Melo, C. H. de, 2008, p. 107).

Tarsila do Amaral também parece colocar-se livre ao usar o livro como suporte para suas experiências estéticas, o que o faz, por exemplo, ao não assinar nenhuma das capas. Em 'Pau Brasil' (Figura 6), a artista altera o formato da bandeira brasileira, o que denota um caráter transgressor, próprio do discurso daquele grupo. Este fato também ocorre na capa de 'Onde o proletariado dirige' (Figura 6), que carrega os preceitos do grupo Pau Brasil relacionados aos ideais da antropofagia. Na recorrente busca pela identidade nacional, o discurso de parte daquele grupo reflete, ainda, seu interesse pela cultura indígena, o que pode ser observado na capa de 'Cobra Norato' (Figura 7), de Flávio de Carvalho.

Figura 5: Pau Brasil e Onde o proletariado dirige, 1925 e 1932, capas de Tarsila do Amaral. Fonte: MELO, Chico Homem de (org), 2008, p. 121 e 171
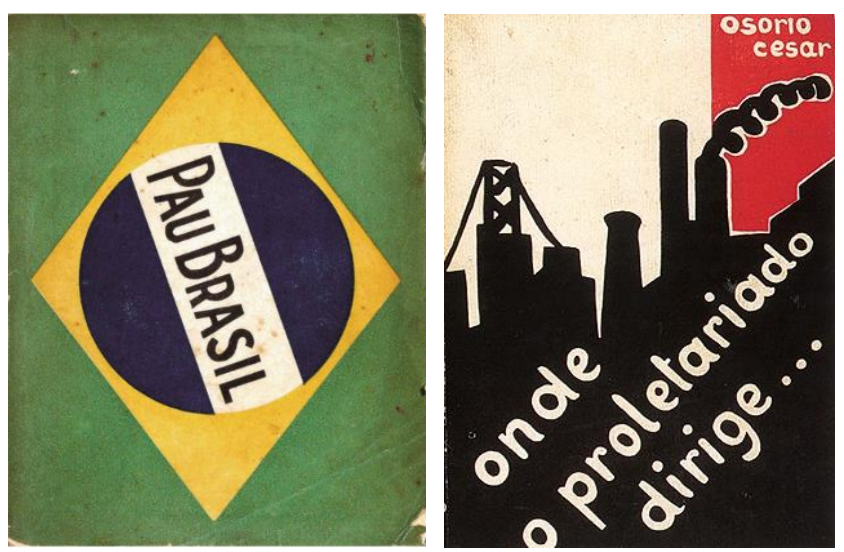

Anais do 9o Congresso Internacional de Design da Informação | CIDI 2019 
Libertário e transgressor, o grupo dos modernistas possuía em seus discursos a clara ideia da finitude ao romper com as regras presentes e ao constituir outras novas, vinculadas permanentemente ao ideal do novo. Ainda que possuíssem discursos coletivos pautados em tais preceitos, era possível observar subjetividades próprias de cada um daqueles autores, como nas experiências produzidas junto ao universo do livro.

Em relação ao caráter de ruptura, inerente aos manifestos modernistas do Grupo de 22 e de seus desdobramentos em o Pau Brasil e Verde Amarelo, é possível correlacioná-lo ao que as teorias do sujeito determinarão a partir do conceito de busca da verdade e que norteará as condições necessárias para o conhecimento, empreendendo a luta em delimitar as fronteiras entre o que seja verdadeiro e aquilo que seja falso. Na teoria foucaultiana, tal conceito é compreendido, em parte, por meio da noção de parrhesía, ou seja, dizer verdadeiro. Tal noção entende que aquilo que é discurso, portanto, o que é dito, e a vida concreta daquele (o sujeito) que discursa, ou diz, devem ser indissociáveis. Deste modo, prática e logos, pensamento e ação, devem caminhar juntos, promovendo, desse modo, o que é verdadeiro:

Etimologicamente, o termo grego parrhesía significa: dizer a verdade. Em um primeiro momento, este termo teve um sentido especificamente político, o direito que tinha todo cidadão de dizer tudo o que pensava aos seus governantes (...). Como muitos outros conceitos e este aspecto sendo

particularmente relevante para Foucault, também a noção de parrhesía se deslocará do vocabulário

(...) da prática política para a das formas da subjetivação (Castro, E. em Nalli, M.\& Mansano, S. R. V (org.), 2016, p. 96).

Em Foucault, tal conceito de verdade (parrhesía) se dará como um modo de ser da subjetivação do sujeito, em que dizer tudo sempre implicará uma espécie de combate que deverá colocar aquele que a profere em situações de risco, "(...) sempre há parrhesía quando o dizer-a-verdade se diz em condições tais que o fato de dizer a verdade, e o fato de tê-la dito, vai ou pode ou deve acarretar consequências custosas para os que disseram a verdade" (Foucault, 2005, p. 55).

Ao introduzirem a ideia de uma nova arte nacional baseada nas vertentes das vanguardas europeias, ao buscarem fomentar tais discursos por meio de teorias espargidas em capas de livros, livros de artista (precursores à época), jornais, manifestos e eventos como o do Teatro Municipal em 1922, o grupo de artistas e escritores modernistas crê em uma verdade validada tanto por suas práticas criativas, quanto por seus precedentes na Europa. É a crença sólida de que portavam a verdade em seus discursos - verdade esta presente tanto no que diziam, quanto em suas obras. Este fato faz com que aqueles autores irrompam com um sistema consolidado no País em torno do que acreditavam estar relacionado aquilo que era próprio do passadismo, logo, que impedia a criação livre e, no que concerne à parrhesía, a liberdade da palavra.

Tendo como fim a verdade, é preciso destacar, ainda, o tipo de singularidade ou subjetivação que define os agentes em seus atos e em suas tomadas de decisão: Mário de Andrade $^{6}$ dá à Anita Malfatti a incumbência - um dos sinônimos de autoria, de ter sido ela a autora daquilo que lhes deu "uma primeira consciência de revolta e de coletividade em luta pela modernização das artes brasileiras "7" (Andrade apud ALMEIDA, 2014, p. 21). Ela que, ao proferir sua verdade, teria sido vítima ou objeto da incompreensão de Monteiro Lobato.

Ao romperem com o tradicional formato de produção do livro a partir do Livro de artista, autores como Flávio de Carvalho, Lasar Segall e Di Cavalcanti apoderam-se de um suporte anteriormente compartilhado com outro autor, o escritor. Seus discursos deveriam, ali, ter plena liberdade de ser articulados sob suas verdades. Seria esse o modo de afirmá-las, tão importante como o próprio conteúdo do que é verdadeiro, assim como quando Tarsila do Amaral rompe com as regras da autoria, impostas tradicionalmente à sua época, destituindo-se da assinatura em sua obra na capa do livro.

\footnotetext{
${ }^{6}$ Mario de Andrade em ALMEIDA, P. Mendes, de. De Anita ao museu. O modernismo, da primeira exposição de Anita Malffati à primeira bienal. São Paulo: Terceiro nome, 2014, p. 21.
} 
Em ambos os extremos, o discurso modernista parecia apoiado a uma verdade que deveria aluir ou afetar aquele que a recebesse. Este fato nos faz compreender que os lugares de subjetivação daquele grupo, ou de seus sujeitos, encontravam-se fundamentados por meio da necessidade em enunciar suas verdades, o que não parecia bastar-se ou restringir-se à obra, mas a outras formas de discurso, como a própria palavra, o que denota um dos jogos de poder, posto que, "nos procedimentos de governo de si e dos outros, o sujeito pode ver-se mediante a obrigação de dizer a verdade tanto na relação consigo, quanto na relação com os outros" (Fernandes, 2012, p. 87).

Figura 6: 'Cobra Norato', capa de Flávio de Carvalho, 1931 e, na sequência, 'Fantoches da meia-noite', capa de Di Cavalcanti, 1921 e 'Mangue', capa de Lasar Segall, 1943. Fonte: MELO, Chico Homem de (org), 2008, p.172, p.107 e p. 226.
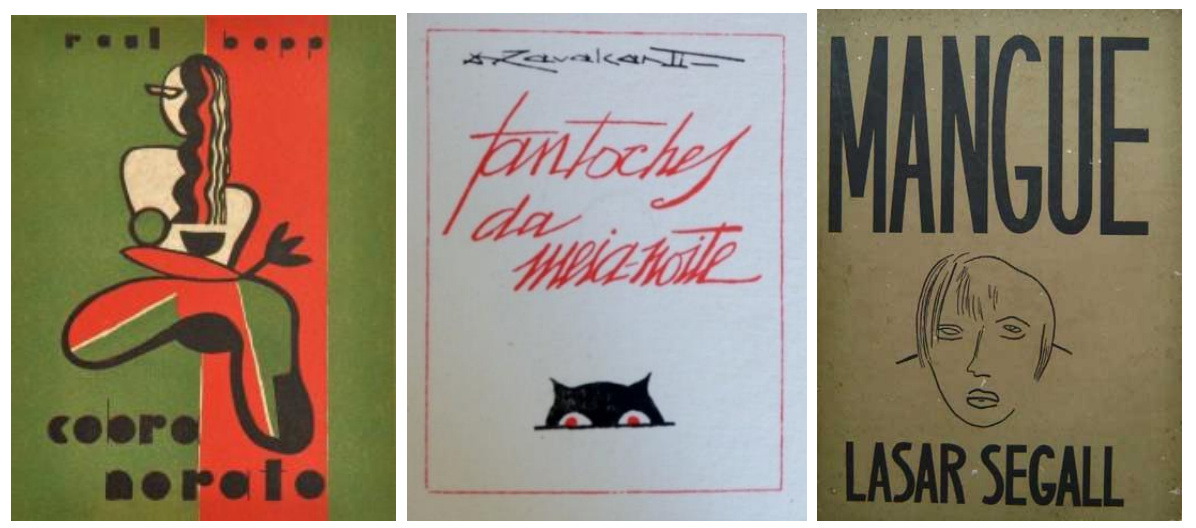

\section{Sem margem à subjetivação}

Finalmente, entre os anos de 1950 e 60, junto ao grupo dos construtivistas nos nomes de Ivan Serpa, Emilie Chamie, Moysés Baumstein e Amílcar de Castro, evidenciamos que ainda que de ruptura, eram menos libertários os discursos relativos a este movimento, que irá se dar no Brasil a partir da segunda metade do século XX. Nas artes, esta vertente surge no País em meio a uma espécie de esgotamento da chamada arte de vanguarda de até então, o que certamente não coloca um fim à produção anterior, mas marca a chegada de um novo discurso:

A afirmação não implica, sem mais, que, com o advento do concretismo, se exaure o modernismo brasileiro, que ele simplesmente deixa de existir. Quer dizer, apenas, que ele deixa de ser reconhecido pelos setores da vanguarda artística brasileira (e é essa sua autoimagem) como o carro-chefe da tarefa da modernidade (Leonídio, 2013, p. 97).

Logo, o discurso se altera, o que pode ser evidenciado no depoimento de Ferreira Gullar ao afirmar que, tais "manifestações não brotaram como resultado natural da evolução da moderna pintura brasileira e, sim, como reação a ela” (Gullar, 1998, p. 232).

O Construtivismo esteve envolvido com ideologias fortemente desenvolvimentistas, relacionadas à industrialização e influenciadas de forma direta pela arte concreta suíçaholandesa representada por Max Bill e Theo van Doesburg. Era centrado na geometria e no rigor estrutural e deveria originar uma arte para fins úteis, o que teria levado a uma ruptura entre a produção das artes gráficas de até então e aquela gerada por um novo comportamento das artes aplicadas, ligadas ao funcionalismo:

Até o surgimento da Bauhaus (1919-32) predomina o pintor/gravador/ilustrador, cuja função atinge as artes aplicadas sem estar necessariamente voltada para os meios de impressão ou para os problemas de percepção próprios da linguagem da comunicação (Wollner, 1983).

Um ponto relevante e que se pretende destacar é que o caráter matemático e lógico do discurso racionalista não deveria deixar margem à subjetivação. Regras de layout e modelos de diagramação direcionados a certa função deveriam prever um resultado final, tanto da 
produção, quanto da recepção do público e, portanto, não expressar seu criador. Neste sentido, no período histórico em que o design afirma-se como campo, a figura do autor passa a estar vinculada à condução de uma metodologia e linguagem universais.

Em meio a este contexto, a produção artística e de artes gráficas no País sofre grandes transformações. Apoiadas por críticos como Mário Pedrosa (1900-1981) e artistas como Geraldo de Barros, as tendências funcionalistas e concretas passam a alterar drasticamente o discurso artístico e a colaborar na construção de um campo discursivo e ideológico que envolvia a afirmação do design no Brasil.

O caráter racional e matemático desse discurso o coloca em oposição direta à arte figurativa, em que a emoção se opõe à razão. $\mathrm{O}$ autor da imagem construtivista baseava-se essencialmente em seu intelecto para produzir uma arte pautada na geometria, em que a repetição de formas, elementos e estudos de cores deveriam ser utilizados, sem distinções, por aquele grupo de artistas e designers. O autor construtivista deveria decidir de que maneira ordenar uma série de fórmulas e modelos que, exatos, não deveriam sofrer interferências expressivas ou emocionais. Portanto, sendo conduzido por tais regras, deveria objetivar tal racionalidade que, dessa maneira, não daria vazão a erros ou surpresas. Neste sentido, aquela nova linguagem estética deveria ser representada coletivamente, como em coro:

Poderíamos resumir os elementos de diferenciação das duas concepções artísticas nesses termos: a figurativa é a arte sentida e a abstracionista é a arte pensada. A arte abstrata não convence o público porque não se funda na sensibilidade, mas na inteligência. Portanto, não será sentida antes de ser compreendida. [...] O caráter objetivo das novas formas produz uma emoção intelectual [...].Evidentemente, porém, o problema da arte não se resolve pela física e nem pela matemática. Existe todavia uma afinidade que faz com que as resoluções do artista em termos artísticos corresponde, aquilo que em termos de ciência resolve o cientista. [...] A escultura moderna se endereça para a conquista do espaço, [...] a grande arte do nosso século é a arquitetura [...]. De outra parte a pintura de cavalete não satisfaz mais as exigências da nova estética. (Brest apud Amaral, 1977, p. 97-98).

Nos anos 1950, o discurso construtivista ainda havia sido fortemente aplicado à produção do livro. Neste período, MELO, Chico Homem (2008) destaca o que chama de "poucas, mas contundentes, incursões do design modernista no campo editorial" (Melo, Chico Homem, 2008, p. 294), entre elas estão 'A canção brasileira' e 'Jangada' de Ivan Serpa e, ainda, a série 'Poemas' de Amílcar de Castro.

Figura 7: 'A Canção Brasileira' e 'Jangada', capas de Ivan Serpa, 1957 e 1959. Fonte: MELO, Chico Homem de (org), 2008, p.294

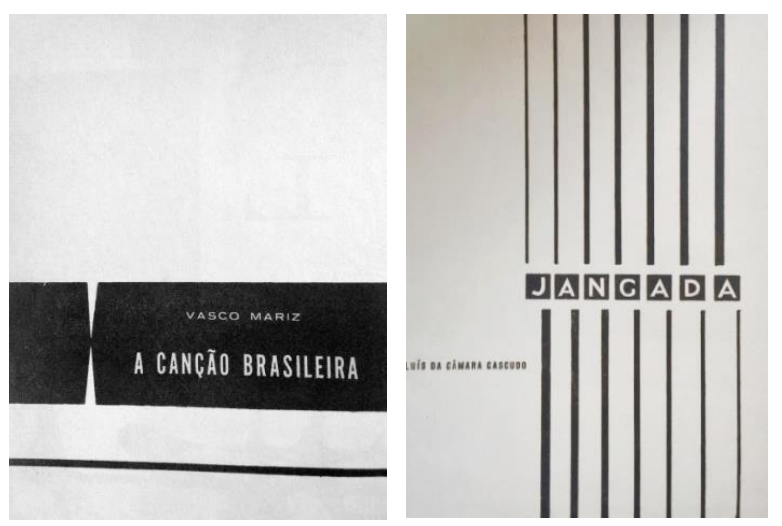


Alcântara, C., Tavares. M. | Autoria e informação visual: design e artes gráficas no projeto editorial do

Figura 8: 'Poemas', capa de Amílcar de Castro, 1958. Fonte: MELO, Chico Homem de (org), 2008, p.297

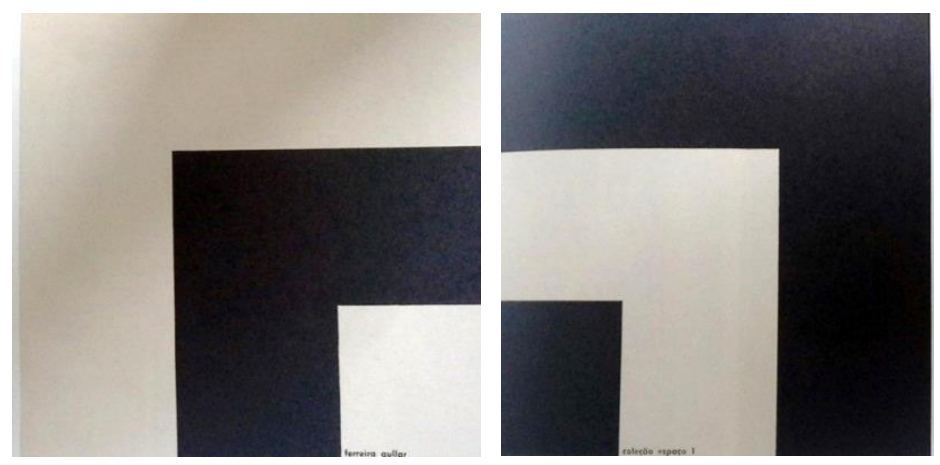

A partir dos anos 1960, merecem destaque as produções de Emilie Chamie e Moysés Baumstein. O primeiro é formado pelo IAC (Instituto de Arte Contemporânea) do Masp (Museu de Arte de São Paulo Assis Chateaubriand) e em suas produções ligadas à poesia práxis ${ }^{8}$ é possível destacar uma série de preceitos funcionalistas, marca que fica evidente quando MELO, Chico Homem (2008) ressalta tal fato utilizando a definição de "escola modernista" (2008, p. 378).

Figura 9. 'A fala e a forma' e 'Poesia Práxis e '22', capas de Emilie Chamie, 1963 e 1966. Fonte: MELO, Chico Homem de (org), 2008, p.378

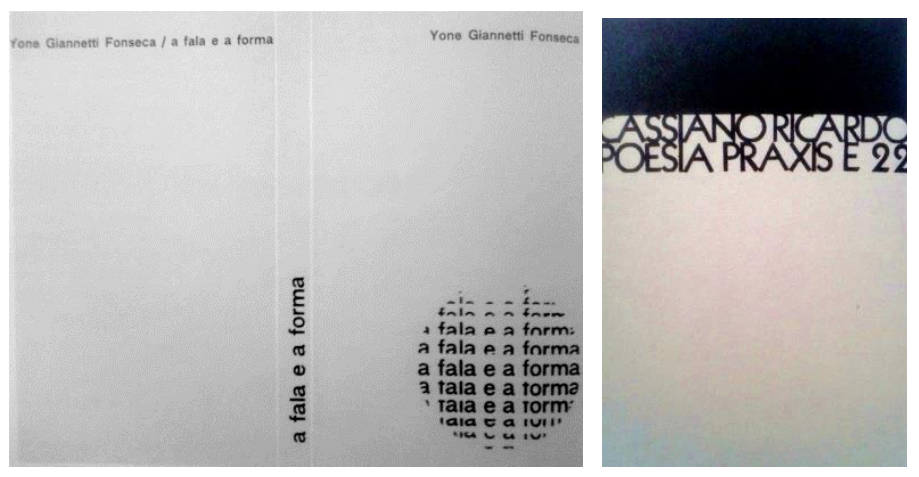

Considerado um dos mais bem-sucedidos projetos modernistas de design de livros, a série Debates tem projeto gráfico de autoria de Moysés Baumstein, que "adota um sistema com uma identidade visual fortemente afirmada, no qual predominam as invariantes" (MELO, Chico Homem, 2008, p. 380).

${ }^{8}$ A poesia-práxis foi uma corrente liderada por Mário Chamie, que, a partir de 1961, passou a adotar a palavra como organismo vivo gerador de novos organismos vivos, ou seja, de novas palavras. 

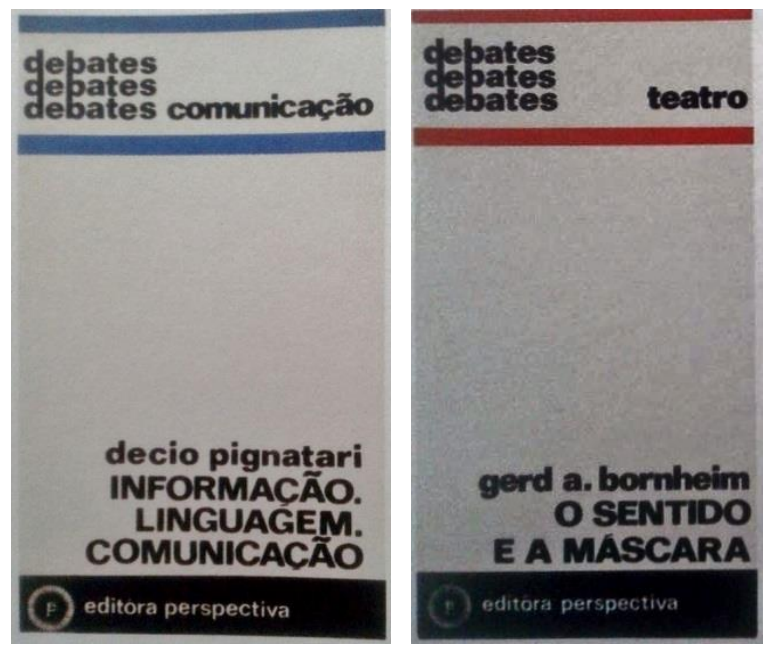

Todos os projetos citados possuem em comum o fundo branco e o destaque à materialidade da página, o que parece um dos preceitos daquele discurso visual, bem como a utilização da tipografia como elemento plástico. Dos três grupos analisados, este é o que mais se apresenta como discurso de modo tangível, remetendo-nos à ideia de metodologia ou, mesmo, de escola.

O conceito de metodologia remete a relação de poder que se dá por meio da atribuição de uma regulamentação própria à objetivação de uma atividade ou a produção final de uma série de bens, tomando como exemplo, a comunicação, a arquitetura e o produto industrial. Ao tratar das relações de poder que envolvem o discurso, o sujeito e consequentemente seus posicionamentos como autor, Foucault (2014) descreve as relações entre indivíduos e grupos: "(...) se falamos do poder das leis, das instituições ou das ideologias, se falamos de estruturas ou mecanismos de poder, é na medida somente em que supomos que alguns exercem um poder sobre outros" (Foucault, 2014, p. 129).

Relativamente às distinções que definem as relações de poder propriamente ditas, determinaremos primeiramente sua diferenciação acerca das chamadas relações de comunicação, aquelas que ocorrem a partir da "transmissão de informação por meio de uma língua, um signo ou qualquer outro meio simbólico" (Foucault, 2014, p. 129), mas que nem sempre envolvem relações de poder impostas por meio de uma sistematização de técnicas de condução. Para Foucault (2014, p. 129), "comunicar é sempre certa maneira de agir sobre o outro ou os outros", mas relações de poder propriamente ditas carregam uma série de propriedades distintas e que as diferenciam das puramente comunicacionais e que não possuem como fim "a dominação de homens sobre homens" (Foucault, 2014, p. 130). Portanto, tais relações se apoiam, mas nem sempre se encontram em um mesmo propósito.

Quando nos remetemos ao conceito de morte do autor, proferido por Foucault (2006, p. 79), observamos que este tem relação intrínseca com a noção de que, ao assinar a obra, o indivíduo passa a existir em outra instância, naquela em que sua identidade civil ou social deixa de existir. A autoria coletiva em torno do grupo construtivista, a partir de um discurso unitário, que não deixasse (ou não idealizasse) o afloramento ou a inserção de vozes que fugissem ao que constituísse o coro, de certa maneira, evidencia essa noção. O grupo fechado em modelos e condutor de metodologias que deveriam ser seguidas à risca para que se atingisse o intento, ou o fim, de se fazer parte daquela ordem, transforma o sujeito empírico (aquele que fala e sente) ao assumir tal modo de sujeição na prática discursiva, ao nome do grupo e ao que este designa e, não, ao nome do autor, o que denota uma clara relação de poder entre os agentes produtores de tais regras e os sujeitos que se sujeitam a estas, do modo como elas se colocam.

Também podemos apontar que, como parte da relação entre técnica e capacitação, estava a noção de liberdade dos indivíduos, uns em relação aos outros (Foucault, 2014), logo, é clara a determinação de uma série de modelos definidos em torno da relação entre técnica, 
tecnologia e indústria, e conduzidos por um conceito de escola construtivista. Fato é que a afirmação do design como campo se dá por meio do desenvolvimento de sua metodologia.

Observamos que, diferentemente do sujeito que organiza suas formações discursivas em torno de regras e condutas empreendidas a partir de suas escolhas e que são próprias, muitas vezes, das relações de comunicação, o sujeito da escola, do método ou do modelo, organiza seus discursos coletivamente - ou já os tem preestabelecidos, sendo, portanto, sujeitados. Neste sentido, o ideal construtivista tinha como conduta a ideia de que os nomes de tantos autores se misturassem na obra e que, com isso, não houvesse especificações ou atribuições ao nome do autor. É o que percebemos nas fichas técnicas em que se sobressaem as designações dos escritórios, estúdios ou coletivos.

Neste trabalho, utilizamos o termo conduta ${ }^{9}$ de dois modos distintos, primeiramente atribuído ao conceito de autor como ordenador de formações discursivas e, por meio disso, de regras de funcionamento que poderão ser utilizadas por outros como modos de conduta em determinado campo discursivo (o que seria, por exemplo, próprio das relações de comunicação inerentes às artes e ao design), e, no que se refere às relações de poder sistematizadas, entenderemos conduta a partir do conceito de se conduzir condutas, típico das relações de poder pautadas em disciplinas que objetivem o domínio sistemático, portanto, estruturado por meio de regras de domínio de uns sobre os outros. "A conduta é ao mesmo tempo o ato de conduzir os outros e a maneira de se comportar em um campo mais ou menos aberto de possibilidades. O exercício de poder consiste em conduzir condutas e em rearranjar as probabilidades" (Foucault, 2014, p.133).

É interessante observar que os preceitos construtivistas conduziam operando por meio de uma espécie de regra de adequação. A este respeito, MELO, Chico Homem (2008) lembra que artistas como Wesley Duke Lee e Willys de Castro, a título de exemplo, dedicaram-se esporadicamente ao design e, ao atuarem na área, "inscreveram-se no território da arte construtivista" (2008, p. 324).

Assim, há aqueles que se inscreveram naquele discurso e que, em determinado espaço de tempo, entoaram suas vozes daquele determinado lugar. É o que podemos observar em Amílcar de Castro, que em sua passagem pela arte construtivista atuou no campo editorial por meio dessa linguagem, como vimos na série Poemas. É possível nos basearmos na experiência deste autor e em sua inscrição no grupo dos construtivistas para demonstrarmos como alguns sujeitos, ainda que inscritos em determinados modelos preestabelecidos, produzam experiências subjetivas provenientes de tentativas isoladas, de alguma forma, fugindo às regras e determinando outras, menos rígidas.

Por exemplo, é o que mostra a crítica: quando fala de Amílcar de Castro, Ferreira Gullar (1998, p. 264) utiliza termos como "intuição" e conceitos que giram em torno da ideia de "caráter pessoal" e "linguagem própria". Especificamente acerca desse artista, Gullar descreve uma "dura e solitária indagação" na qual Amílcar de Castro emergiu quando se torna dono de uma "linguagem própria" (Gullar, 1998, p. 264). Nesse sentido, Gullar trata do caráter questionador da personalidade de Amílcar de Castro, o que refletia seu desejo em afastar sua obra da gratuidade.

Posto isto, Gullar (1998) desenvolve seu discurso acerca de certa independência que artistas como Amílcar de Castro mantinham dos grupos nos quais se inseriam, o que ocorreria por meio de determinadas singularidades. Quando cita, por exemplo, o retorno de Amílcar de Castro após sete anos de afastamento, Gullar (1998) se utiliza da expressão "aparente silêncio", que denota o caráter pessoal inserido à trajetória do criador: "O artista está entregue a si mesmo e à sua linguagem potencial que, antes de a obra nascer, é apenas um número indeterminado de possibilidades formais. (...) estaríamos no caos não fosse a vontade de significação que é a origem e o termo do trabalho criador" (GULLAR, 1998, p. 266). Por

\footnotetext{
9 Teoricamente embasado a partir da teoria de gênio de Immanuel Kant e das regras de funcionamento do discurso de Foucault, em ALCÂNTARA, Cristiane. O autor entre o sujeito: modos da subjetivação no fazer do livro de artista. 2017. 206 p. Tese (Doutorado) - Curso de Artes Visuais, Universidade de São Paulo, São Paulo, 2017. Disponível em: <http://www.teses.usp.br/teses/disponiveis/27/27159/tde-30052017144619/ptbr.php>
} 
conseguinte, é evidente o diferente posicionamento tomado por Amílcar de Castro quando inserido no universo do design, neste caso, na produção editorial.

A noção de modelo parece descrever as condições históricas e de lugar em que os discursos são organizados. Nelas, a figura do autor passa a ser um modo de função do sujeito, como um procedimento interno de controle e delimitação do discurso. Ainda assim, é evidente o modo como os discursos construtivistas se organizam coletivamente, como também são concretamente definidos os elementos externos que os produzem a partir de um discurso organizado, homogêneo, o que, de algum modo, dava poder àqueles autores, haja vista que os "(...) sujeitos procuram se inscrever em práticas discursivas que os mostram inscritos em uma situação social" (Fernandes, 2012, p. 59).

Logo, é possível observar que os discursos construtivistas conduziriam o autor ao sujeito diluído no discurso, em que há uma valorização do anonimato em modelos internacionalizados e na linguagem visual universal. Tais ideais eram construídos em torno do indivíduo dissociado de si, diluído em discursos universais, determinados por modelos que seriam definidos pela noção de disciplina e que conduziriam os modos de crer e de organizar discursos. Como lembra-nos Foucault (2008), tornando, desse modo, visíveis àqueles que constituem determinado campo discursivo:

O exercício da disciplina supõe um dispositivo que obrigue pelo jogo do olhar; um aparelho onde as técnicas que permitem ver induzam a efeitos de poder, e onde, em troca, os meios de coerção tornem claramente visíveis aqueles sobre quem se aplicam (...) (Foucault, 2008, p. 143).

Este fato não teria impossibilitado que ocorressem, por exemplo, posicionamentos distintos entre aqueles autores, como teria havido, como vimos, com Amílcar de Castro em relação ao discurso concretista e, que tais embates em torno de um mesmo discurso produzissem grupos distintos - como o Concretista, o Grupo Frente (1954) e, mais adiante, o Neoconcretista, e que desenvolveriam discursos que objetivavam ampliar as propostas concretistas, conduzindo, assim, a modos mais experienciais e indagatórios, afinal, as regras discursivas são "(...) condições de existência de um enunciado, de um discurso, que dão sua singularização, inclusive em termos históricos" (Nalli, 2005, p. 158). Diante disso, naquele mesmo momento e da necessidade de experiência e indagação, autores contemporâneos entre si e sob a égide dos discursos construtivistas, diluem-se em outros e distintos discursos envolvidos ao saber.

\section{Considerações finais}

Com base no conceito foucaltiano de 'função autor' - este utilizado na análise dos variados posicionamentos de artistas gráficos e designers brasileiros contextualizados em distintas fases do século XX e entendidos como produtores de discursos inseridos às suas próprias visualidades, foi possível que empreendêssemos uma ampliação do tema da autoria envolvida à produção da informação visual no âmbito do projeto editorial. As subjetividades, relacionadas aos processos de criação das peças gráficas, antes referidas, firmam-se ao se condicionarem pelas continuidades e rupturas dos espaços-tempos vividos - próprios dos contextos históricosócio-econômicos de cada artista e/ou designer. Assim sendo, os autores, aqui citados, tiveram, sobretudo, a função primordial de delimitar e organizar discursos, de selecionar e combinar repertórios estruturados a partir de linguagens. Ao determinarem suas vocações específicas, esses sujeitos situam-se fortemente influenciados, se não determinados, por uma coletividade de enunciados significativos que expressam formalmente maneiras de pensar, agir, fazer e saber.

\section{Referências}

Agreli, J. Canastra: o sticker como retribalização na contemporaneidade, na prática do potlatch e da intervenção urbana, por meio da cibercultura (2013). Tese de Doutorado em Artes Visuais. Universidade de Brasília, Brasília. 
Alcântara, C., Tavares. M. | Autoria e informação visual: design e artes gráficas no projeto editorial do século 20

Aimeida, P. M. de (2014). De Anita ao museu. O modernismo, da primeira exposição de Anita Malffati à primeira bienal. São Paulo: Terceiro nome.

Fernandes, Cleudemar Alves. (2012). Discurso e sujeito em Michel Foucault. São Paulo: Intermeios.

Foucault, M. (1995). O sujeito e o poder. In P. Rabinow, H. Dreyfus, \& M. Foucault (Eds.). Uma trajetória filosófica para além do estruturalismo e da hermenêutica. Rio de Janeiro: Forense Universitária.

. (2005). A ordem do discurso. 12a. edição. São Paulo: Edições Loyola.

- (2008) Arqueologia das ciências e história dos sistemas de pensamento. Coleção Ditos e Escritos vol. II. Rio de Janeiro: Forense Universitária.

Barros M. M. (org). (2014). "Ditos e escritos”, volume IX: Genealogia da ética, subjetividade e sexualidade. Org.: Manoel Barros da Motta. Trad.: Abner Chiquieri. Rio de Janeiro: Forense Universitária. . (2002). História da loucura, Trad. José Teixeira Coelho Netto, São Paulo: Perspectiva.

Gullar, F. (1998). Etapas da arte contemporânea. Do cubismo à arte neoconcreta. Rio de Janeiro: Revan.

J. Carlos em Revista [Catálogo]. São Paulo: Centro Cultural Correios e Instituto Memória Gráfica Brasileira, 2016, p. 63

Leonídio, O. (2013). Caminhos comoventes: Concretismo, neoconcretismo e arte contemporânea no Brasil. Pontifícia Universidade Católica do Rio de Janeiro (PUCRio). Rio de Janeiro. Disponível em < http://www.revistaviso.com.br/pdf/Viso_13_OtavioLeonidio.pdf>. Último acesso: 22 jan. 2017.

Melo, C. H. de (org). (2008). O design gráfico brasileiro: anos 60. São Paulo: Cosac Naify.

Nalli, M. (2005). Sobre o conceito foucaultiano de discurso. In: ORLANDI, L. B. L. (Org.). A diferença (pp. 151-169) Campinas, SP: Ed. da Unicamp.

Orlandi. E. P. (1996). A linguagem e seu funcionamento: As formas do discurso. Campinas: Pontes.

Pecheux, M (1998). Sobre a (des)construção das teorias linguísticas. Cadernos de Tradução, 4, 35-55.

Woller, A. "Pioneiros da comunicação visual". In: Agitrop Revista Brasileira de Design. Ano I, nº 11. Disponível em $<$ http://www.agitprop.com.br/index.cfm?pag=repertorio det\&id=16\&titulo=repertorio $>$. último acesso: 20 mai 2014.

\section{Sobre as autoras}

Cristiane Alcântara, PhD, UFU, Brasil <cristiane.alcantara@ufu.br>

Monica Tavares, PhD, USP, Brasil<mbstavares@usp.br> 